\title{
Understanding the Use and Motivation of Digital Music Technologies among Middle- Aged and Older Adults
}

\author{
Mao Mao \\ University of Cambridge \\ Cambridge, UK \\ mm992@cam.ac.uk
}

\author{
David A. Good \\ University of Cambridge \\ Cambridge, UK \\ dg25@cam.ac.uk
}

\begin{abstract}
Active participation in everyday life and social activities is essential for older adults to maintain wellbeing. The notion of "Active Ageing" brings a new angle to understand the challenges and opportunities of emerging technologies. We report results from a survey study that compares the uses and motivations of using digital music technologies amongst middle-aged and older people and quantifies the effects of motivations. Getting social connectedness is a key predictor for more frequent use and sharing with digital music technologies. Group participation contributes to higher likelihood of using digital music technologies and more frequent use. The findings were triangulated with situated use and music group activities drawn from our prior ethnographic study. We also highlighted that age was a relevant but not prominent factor in technology use and motivation.
\end{abstract}

Older people, Motivation, Technology adoption, Music, Identity.

\section{INTRODUCTION}

Over the last two decades, $\mathrm{HCl}$ and human factors research around the elderly has been dominated by deficit-driven approaches when designing and developing technologies [53]. As a consequence, a large number of research treats ageing as a "problem" to be fixed and has been focussed on developing assistive systems to overcome cognitive and physiological deficiency. However, influenced by the social and critical gerontology literature and the notion of "active ageing" [55], researchers recently suggest a more active way to reconfigure "the old age" in $\mathrm{HCl}$. They argue that older adults are able to actively engage in social activities and give back to the community $[5,36,37]$, so as to maintain social and physical wellbeing. Only considering age differences limits the scope of research and is not able to draw the whole picture of technology use.

In particular, researchers direct attention to how technology use is situated in everyday life and social activities [49,53], and how "action, context, social and technological factors" mutually influence the use of technology [32]. We adopt Lucy Suchman's notion of "situated action", which argues that "every course of action depends on essential ways on its material and social circumstances" [48:70]. In this study, we report results from a survey study comparing the motivating factors of using digital music technologies amongst middle-aged and older people who participate in musical groups and who do not. We chose music groups and the situated use of digital music technologies for three reasons. First, community-based music activities are popular among middle-aged and older adults in the UK and Europe [20]. Interacting with music among this population lies in a spectrum of possibilities that are defined, at one end, by conventional or digital listening devices, and at the other, by a collection of interconnected technologies (e.g., PCs, MP3, cell phones) [30]. As such, we thought that they would be able to relate the use of various technologies to the elders' everyday music participation. Second, community-based music groups, ranging from informal ones (i.e., music festivals, workshops, events) to formal performance ones (i.e., choirs and orchestras), provide "social spaces" [51] for active engagement. Prior research on active ageing and music made it clear that participatory music in community contributed to the formation of social bonding, and improved wellbeing in later life via three major routes: providing purposes, supporting autonomy and control, and assisting social affirmation [2]. We assumed that these routes would enable various levels of group participation and identification, with which we could contextualise technology use and motivation of the middle-aged and older adults.

A few previous studies provided quantitative evidence of what motivating factors predict listening 
practices on social media, the choice of listening devices, and the use of playlists [26,27]. Community music practitioners have been interested in opportunities brought by cloud-based technologies and streaming services [15]. However, a gap exists between adopting cloud-based technologies and community music participation, as such technologies were not designed for the elders' purposes and were hardly adopted by them without any difficulty [43]. Although a few previous studies provided qualitative evidences of the appropriation and motivation of online media systems (e.g., online video creation [17], blogging [5]), it remains unclear how the elderly would be motivated to use digital music services for their routines and social activities [28]. Our prior ethnographic study [33] showed that digital music technologies sustained the routine practices of group music making. To explore this further and triangulate the findings, we surveyed the use patterns of digital music technologies among middleaged and older people and quantified the effect of motivation in terms of age and group membership. We ask if and how age is related to the use and motivation of digital music technologies:

- RQ1: How is age associated with the use of digital music technologies?

This study utilises the uses and gratifications approach and social identity theory. Uses and Gratifications (U\&G) theory examines how people use media to meet their own psychological and social needs [23]. Social identity theory concerns the mechanisms of the development of shared identities, through which people prescribe and evaluate who they are, how others see them, and how they should behave $[34,50]$. To test the role of these theories in explaining technology use, the following research questions are asked:

- RQ2: How are U\&G motivations associated with the use of digital music technologies?

- RQ3: How are U\&G motivations associated with the probability of being a member of a music group?

- RQ4: For music group participants, how are U\&G motivations associated with the probability of being users of digital music technologies?

This study contributes a nuanced picture of the situated use of digital music technologies among middle-aged and older people, specifies how individual and social motivations affect the adoption, and how these motivations are associated with age and social identification. We address the gap between theoretical motivating factors and the realworld practices by contextualising the quantified effects of motivations with our prior ethnographic findings that reflected situated use of digital music technologies in the discussion. The overall objective is to be specific about the heterogeneity of the ageing population and be sensitive to their situated needs and motivations.

\section{THEORETICAL BACKGROUND}

\subsection{A Working Definition of Digital Music Technologies}

In this study, we adopted and adapted Krause and North's definition of digital music technologies [26] alongside our prior ethnographic study [33], that "technology, application, and devices that allow users to interact with music digitally". Such technologies include, but are not limited to, online streaming services (e.g., Spotify, GrooveShark, Last.FM, Amazon Prime music), social systems with functions of music (e.g., YouTube), music applications (e.g., iTunes), tools and devices (e.g., MP3s, tablets, mobile phones, and wireless sound systems).

\subsection{Motivations and Adoption of Technology}

Uses and Gratifications (U\&G) theory originally concerns mass media consumption and is under the assumption that audiences actively select media based on their psychological and social needs rather than passive receiving it [23]. More recently, Internet researchers theoretically position the Internet Technology as a "legitimate subject of mass communication and social science research" and applied the U\&G approach to studies of technology uses and motivations [42]. U\&G theory has been found useful in understanding the needs and motivations of technological systems. By synthesising these studies with music technology literature, we identified two relevant motivations to our case of music participation:

- Socialising and communication, which refers to maintaining social relationship to get social support and a sense of belonging $[8,27]$. In some studies [27], entertainment overlaps with information and discovery.

- Information and discovery, which is the instrumental purpose of receiving information and knowledge and discovering new music $[22,27]$.

A relevant line of research concerns the adoption of emerging technologies. Having an "interdisciplinary" nature [3], $\mathrm{HCl}$ research on the adoption of technology has been influenced by a few differing disciplinary perspectives [32]. One strand of research is the Technology Acceptance Model (TAM) (e.g., [14]), which has been widely used in Management Science and Information Systems [32]. TAM investigates whether a system is adopted or not (usually in business companies) based on two constructs: perceived usefulness and perceived 
ease of use. Prior research argued that older adults have a benefit-driven approach to new technologies, which resonates with "perceive usefulness" in TAM [14] and other theoretical constructs such as "meaningfulness" and "perceived quality of products". For example, youth tend to produce digital videos for self-expression, while the contents of videos created by the elderly are mainly for archive use [17]. Also, the perceived control and confidence of using technologies (e.g., locus of control and self-efficacy in [1]) play a role in technology use when the elderly is already aware of the innovations $[13,35]$. However, TAM has been criticised that it fails to account for "the true complexities of socio-technical relationship", as TAM-derived findings are constrained to "certain contexts" (i.e., a particular system in a particular corporation) [32]. Another perspective of adoption is drawn from social studies of technology. Such studies observe a large number of complex and mutually interdependent factors [32] of the contexts and actors and seek to answer questions such as how are technologies shaped by users, and what it means to be "adopted". Relevant concepts and theories include technology appropriation [16], the domestication theory [46], and social practice theory [45], etc. However, a detailed review of social studies of technology is beyond the scope of this work. We will contextualise the findings on motivating factors with the situated use from our prior ethnographic studies in the discussion.

\subsection{Social Identity and Music Participation}

Social identity theory argues that we can think of ourselves in different ways and in different contexts: sometimes in terms of personal identities, and sometimes in terms of social identity and group membership (how we see others and how we think others see us) [50]. Social identification with groups, no matter the group is small or large in scale, structures people's perception and action [40]. Social psychology research explains the mechanism underlying the associations. One strand of thought argues that the image of a group emerges and grows as people participate. An individual's knowledge that "he belongs to certain social groups together with some value and emotional attached to that group membership" accumulates with such images [50], and may contribute to intentions of consumer behaviours [47]. Another mechanism uses a self-categorisation perspective and argues that the processes of social identification are future-oriented and dynamic [40]. The future-oriented notion applies to the enactment of digital identities, and has been highlighted in social media studies and online media practices [39,54]. For example, Orzech et al. found that retirees have an outward lens with their camera and tend to be observers in online photo sharing practices [38].

\section{METHODOLOGY}

\subsection{Participants}

To answer the research questions above, we conducted an online survey among people who are aged over 40 around United Kingdom in early 2017. Participants were recruited through a combination of professional online survey platforms (Qualtrics and Prolific). Only those with an approval rate $^{1}$ of $90 \%$ or higher were invited to participate. As a further quality check, responses that failed in more than 3 of the 4 quality checks (10.5\%) were excluded from analysis. The average age of the finalised sample was $55(N=153,57.5 \%$ female, $47.1 \%$ aged over 55$)$. Thirty-four (22.2\%) had formal music group memberships (i.e., choir, orchestra), 33 (21.6\%) had informal music group participation experience (i.e., music workshops, classes at U3As, bands), and $86(56.2 \%)$ had no prior experience of music group participation. One hundred and nine $(71.2 \%)$ were in employment and $28(18.3 \%)$ retired, and $15(9.8 \%)$ were seeking employment. Fifty-five (35.9\%) had preliminary-tointermediate education, 59 (38.5\%) were university educated, and $39(25.5 \%)$ had master or higher degrees. Comparing the demographics of two cohorts (younger than 55 vs. aged 55 and above), we found only significant difference in employment status $\left(\chi^{2}[3]=18.86, p<0.01\right)$. In the younger group, $64(84.0 \%)$ were in employment and 5 (6.2\%) were retired. In the older group, 41 (56.9\%) were in employment and $23(31.9 \%)$ were retired. Figure 1 presents the distribution of age and music group memberships by gender.

It is not a representative sample of the general middle-aged and older population. Rather, it is a more tech-savvy sample because we used the online survey instrument and partially targeted people with any form of music group participation. However, such relatively homogenous sample is sufficient for our attempt to investigate the use and motivation of digital music technologies. Previous studies $[4,24,25]$ have shown that online survey platforms and crowdsourcing tools (i.e., Amazon's Mechanical Turk) are suitable for user studies (even among older population) with special care in the design of the measurements.

\footnotetext{
${ }^{1}$ Approval rate is calculated by the percentage of studies for which the participant has been approved (see http://help.prolific.ac/general/prolifics-codebook).
} 

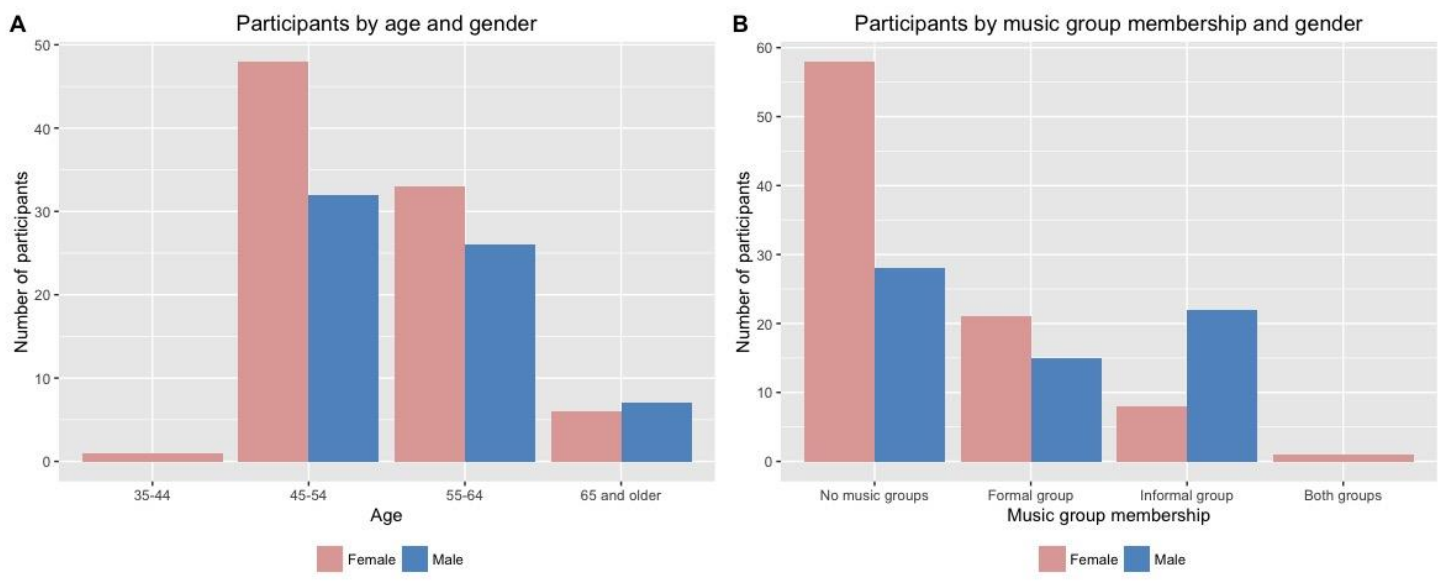

Figure 1: Participants demographics

\subsection{Design of the Survey}

We developed the survey items from literature and our previous ethnographic findings [33] with local retirement communities. The survey questions were developed through extensive piloting. The final items were piloted again with English-speaking middleaged and older people in the local community.

We asked the participants': (i) use of a set of digital music technologies; (ii) use frequency of a series of practices related to digital music technologies; and (iii) sharing frequency with music group members and with family and friends. The questions of use and sharing practices were not restricted to one or some specific online music services, unless explicitly indicated, and were grounded in our earlier ethnographic findings [33]. The analysis of use pattern and sharing frequency is discussed in the succeeding sections. It is important to note that the use in our survey represent participants' impressions of their past and present activity, rather than behavioural data.

The main independent variables were associated with theories above and measured with Likert scales:

Uses and Gratifications, with which 6 items were adapted from two dimensions of the U\&G theory: social connectedness ( 3 items) and information seeking ( 3 items). All items asked: "Using music streaming services has enabled me to ..." and were measured on a 7-point Likert scale. An instance of item of social connectedness was "strengthen my relationship with friends". It is important to note that the two U\&G dimensions, as well as other theoretical factors measured in our study were not exclusive. A participant can be motivated to maintain social relationship and keep updated with information at the same time. The reliability of both dimensions (see Table 1) was above the suggested threshold 0.60 , which was sufficient for exploratory research [19]. A factor analysis was conducted to verify the dimensions (see Table 1).

Table 1: Means, standard deviations, Cronbach's Alphas and correlations of psychological constructs.

\begin{tabular}{|c|c|c|c|c|c|}
\hline & $\begin{array}{l}M \\
\text { (SD) }\end{array}$ & $\alpha$ & $\begin{array}{c}2 . \\
r\end{array}$ & $\begin{array}{l}3 . \\
r\end{array}$ & $\begin{array}{l}4 . \\
\text { r }\end{array}$ \\
\hline $\begin{array}{l}\text { 1.General } \\
\text { computer self- } \\
\text { efficacy }\end{array}$ & $\begin{array}{l}72.52 \\
(18.26)\end{array}$ & .65 & $.75^{* * *}$ & $.25^{* *}$ & .08 \\
\hline $\begin{array}{l}\text { 2.Music-tech } \\
\text { self-efficacy }\end{array}$ & $\begin{array}{l}67.73 \\
(24.96) \\
\end{array}$ & .85 & & $.32^{* * *}$ & .10 \\
\hline $\begin{array}{l}\text { 3.Information } \\
\text { seeking }\end{array}$ & $\begin{array}{c}4.36 \\
(1.49) \\
\end{array}$ & .90 & & & $.69^{* * *}$ \\
\hline $\begin{array}{l}\text { 4.Social } \\
\text { connectedness }\end{array}$ & $\begin{array}{c}3.16 \\
(1.40) \\
\end{array}$ & .83 & & & \\
\hline
\end{tabular}

This survey also included control variables for the second stage of analysis. We measured the general computer use self-efficacy $[10,52](4$ items) and music-tech-specific self-efficacy (4 items) with a series of 11-point scales (the percentage of confidence from 0 to $100 \%$ ). Control variables for gender, education level, and music expertise level were measured as well. Music expertise is a binary variable indicating whether the participants had a higher level formal music training (i.e., having a music degree or qualifications or having received formal singing/instrument training more than the average level of the sample).

\section{RESULTS}

We first compared a) the use pattern and b) sharing frequency of digital music technologies between two cohorts - participants who are younger than 55 and who are 55 and above. At the second stage of the analysis, we started by examining the macro-level differences between those who participated in music 
groups and those who did not, and further analysed the heterogeneity in these two groups.

\subsection{Use Patterns and Sharing of Digital Music Technologies}

Our first stage of analysis set out to answer RQ1. We specified a model of bundled use patterns around digital music technologies; we also investigated if and how bundled use patterns differ across the two age groups. We used factor analysis to extract patterns from 9 items of digital music technology use. The 9 items represented typical practices identified from our previous ethnographic study.

\subsubsection{Bundled use patterns of digital music technologies}

In our study, use was measured with two aspects: bundled use patterns and sharing frequency. As for use patterns, we measured the participants' perceived frequency of use of digital music technologies with a 6-point scale (ranging from daily, few times a week, few times a month, few times a year, almost never and never). Items include: "search for music online", "rate music online", "bookmark music online", "recommend music to someone", "post a comment about music", "upload music to SoundCloud", "record music", "buy musicrelated devices", "learn music online", "email with music groups". As for sharing, we measured the frequencies within music groups ("How often do you share the following ... with music group members?" 6-point scale) and outside groups ("How often do you share the following ... with your family and friends?"). Items for each question included: "digital music files", "links of music online", "sheet music", and "music relevant information".

To extract patterns, we used the principal axis factor analysis (PAF). We analysed the correlation matrix, extracted factors with eigenvalue over 1 , and rotated with the oblimin method. Prior literature showed that PAF is especially appropriate for new scales (given our research population and the domain in music technologies) [21]. Based on the scree plot and the parallel analysis criterion (see [18]), we set the number of factor to be extracted to 2 . The analysis method was appropriate because the KMO (KaiserMeyer-Olkin) of the 10 items was.85, and the correlation matrix was factorable with a significant result of Bartlett's test $(p<0.001)$. The item "search music online" was removed due to low communality after the first iteration. After the second iteration, 2 factors emerged from the 9 items of use frequency, with $57 \%$ of variance explained. The two factors were named based on the common meanings of the items included. Factor 1 was labelled "socialising", and it included practices related to the social aspects of music: commenting and rating on a piece of music, emailing for the purpose of music, and bookmarking a piece of music online. Factor 2 "active interacting" included 5 items concerning active interaction with music online and offline for various purposes: recording music, learning music from online resources, uploading music, buying devices for music, and recommending music to others.

Participants' scores on the two factors (in which the relevant item scores were averaged) appear in Table 2. The factors were ranked with their eigenvalues (socialising -4.65 , active interacting $0.46)$. The factor "active interacting" ranked higher, indicating that it was perceived more frequently among our participants. The reliability of both factors was above .70, and the construct validity of the model was acceptable.

Table 2: Factor means, standard deviations, and Cronbach's Alphas, and standardised loadings.

\begin{tabular}{|c|c|c|}
\hline Items & M (SD) & Loadings \\
\hline \multicolumn{3}{|c|}{$\begin{array}{l}\text { Factor 1: Socialising } \\
(M=2.81, S D=1.09, \alpha=.81, \text { eigenvalue }=4.65)\end{array}$} \\
\hline Comment on a music & $2.71(1.49)$ & .87 \\
\hline Rate music online & $2.45(1.43)$ & .78 \\
\hline $\begin{array}{l}\text { Bookmark a piece of music } \\
\text { online }\end{array}$ & $3.01(1.56)$ & .70 \\
\hline Email & $3.16(1.45)$ & .70 \\
\hline \multicolumn{3}{|c|}{$\begin{array}{l}\text { Factor 2: Active Interacting } \\
(M=2.59, S D=.85, \alpha=.79, \text { eigenvalue }=.46)\end{array}$} \\
\hline Record music & $2.41(1.34)$ & .88 \\
\hline Upload music online & $2.52(1.63)$ & .74 \\
\hline Buy devices for music & $2.52(.99)$ & .69 \\
\hline Learn music online & $2.39(1.37)$ & .65 \\
\hline Recommend music & $3.50(1.16)$ & .52 \\
\hline
\end{tabular}

4.1.2 Cohort effects of uses and sharing patterns We compared the factor scores of bundled use patterns (socialising and active interacting) and discrete use items across two cohorts using the Mann-Whitney $U$ test. There were no significant differences in terms of bundled nor discrete uses across two age groups. We also investigated the age differences on sharing frequencies using the same test. Results showed that the two age groups did not have significant different sharing frequencies within groups $(M=2.14, S D=$

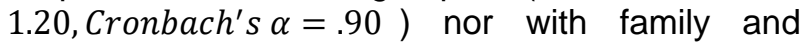
friends $(M=2.18, S D=.99$, Cronbach's $\alpha=.85)$ around digital music technologies.

Taken together, middle-aged participants and older participants in our study did not show significantly different use patterns and sharing behaviour of these technologies. We will explain the impact of motivation in more depth and answer RQ2, 3 and 4 in sections that follow.

\subsection{Motivations Influence on Use Patterns}

At the second stage of analysis, we started by examining how the sharing patterns and bundled 
use frequency related to different motivating factors. The three columns represented three multiple linear regressions using use patterns and sharing frequencies as outcomes respectively. Factor scores of "Active Interacting" calculated in 4.1.1, the averaged item scores of "sharing within groups" and "sharing with family and friends" were used as dependent variables. Socialising did not show any significant results, and we did not include it in Table 3. All three regressions adopted the same set of independent variables. All coefficients in the models were standardised in Table 3.

Table 3: Motivations influence on use and sharing

\begin{tabular}{|c|c|c|c|}
\hline & $\begin{array}{c}\text { Share } \\
\text { within } \\
\text { groups }\end{array}$ & $\begin{array}{c}\text { Share } \\
\text { outside } \\
\text { groups }\end{array}$ & $\begin{array}{l}\text { Active } \\
\text { Inter- } \\
\text { acting }\end{array}$ \\
\hline (Intercept) & 1.32 & 1.22 & 1.43 \\
\hline $\begin{array}{l}\text { Formal } \\
\text { membership }\end{array}$ & 1.00 & .25 & .43 \\
\hline $\begin{array}{l}\text { Informal } \\
\text { membership }\end{array}$ & 9.52 & 3.64 & 6.41 \\
\hline Age & -.01 & -.01 & .00 \\
\hline Gender & .09 & .09 & .03 \\
\hline $\begin{array}{l}\text { Edu } \\
\text { [undergraduate] }\end{array}$ & -3.18 & -3.03 & -6.80 \\
\hline $\begin{array}{l}\text { Edu [master or } \\
\text { higher] }\end{array}$ & -6.27 & -5.11 & -9.13 \\
\hline GC self-efficacy & .00 & .00 & 00 \\
\hline $\begin{array}{l}\text { Music self- } \\
\text { efficacy }\end{array}$ & .00 & 01 & 01 \\
\hline Music expertise & 34 & .73 & .58 \\
\hline $\begin{array}{l}\text { Information } \\
\text { seeking }\end{array}$ & .01 & .00 & .04 \\
\hline $\begin{array}{l}\text { Social } \\
\text { Connectedness }\end{array}$ & .87 & 1.26 & 1.02 \\
\hline Adjusted $R^{2}$ & .60 & .25 & .41 \\
\hline$F(11,141)$ & 21.43 & 5.58 & 10.62 \\
\hline
\end{tabular}

Note: ${ }^{*} p<0.05,{ }^{* \star} p<0.01 ;{ }^{* * *} p<0.001$. All coefficients were standardised $\beta$. Female, 'A level or lower' education level participants were coded zero.

The most important purpose of actively interacting with music and sharing music was to maintain social connectedness. Positive values of $\beta$ indicated that the stronger the social motivation was, the more frequently did participants interact with and share music. Surprisingly, value of music-related information seeking did not play a significant role in active interacting nor sharing with digital music technologies. This was possible that participants came to digital music technologies in support of their music practices and stay connected with others, while attempted to learn about information around music by themselves or via conventional channels (i.e., email, face-to-face communication).

None of the demographics and control variables, except for music expertise and education, showed significant effects on use and sharing. Higher level of music expertise was associated more frequent sharing and active interacting with music. Higher education levels correlated with less frequent active interacting with music. Interestingly, participants with music group memberships perceived themselves interacting with and sharing music more frequently. The $\beta$ of informal membership was larger than that of formal membership in all three cases. How do informal and formal group members differ from each other? In the next section, we proceeded with examining how motivations influence group memberships.

\subsection{Motivations Influence on Memberships}

We investigated the influence of motivation on type of memberships by conducting a multinomial regression (see Table 4). The outcome variable has three levels: no membership, having a formal membership, and having an informal membership. The level 'no membership' is treated as the reference level. All Likert scale ratings were standardised before being entered to the model.

Table 4: Motivations influence on membership

\begin{tabular}{|c|c|c|c|c|c|c|}
\hline & \multicolumn{3}{|c|}{$\begin{array}{c}\text { Informal } \\
\text { membership }\end{array}$} & \multicolumn{3}{|c|}{$\begin{array}{c}\text { Formal } \\
\text { membership }\end{array}$} \\
\hline & $\beta$ & & & $\beta$ & & \\
\hline & \multicolumn{3}{|c|}{$\mathbf{9 5} \% \mathrm{Cl}$ (LB-UB) } & \multicolumn{3}{|c|}{$\mathbf{9 5} \% \mathrm{Cl}$ (LB-UB) } \\
\hline \multirow[t]{2}{*}{ (Intercept) } & -5.44 & .00 & * & -7.92 & .00 & $* * *$ \\
\hline & \multicolumn{3}{|c|}{$(.00, .46)$} & \multicolumn{3}{|c|}{$(.00, .02)$} \\
\hline \multirow[t]{2}{*}{ Age } & .04 & 1.04 & & .08 & 1.08 & \\
\hline & \multicolumn{3}{|c|}{$(.97,1.13)$} & \multicolumn{3}{|c|}{$(1.01,1.16)$} \\
\hline \multirow[t]{2}{*}{ Gender } & 1.47 & 4.33 & ** & .33 & 1.40 & \\
\hline & \multicolumn{3}{|c|}{$(1.45,12.94)$} & \multicolumn{3}{|c|}{$(.52,3.77)$} \\
\hline \multirow{2}{*}{$\begin{array}{l}\text { Edu [under- } \\
\text { graduate] }\end{array}$} & -.33 & .72 & & .30 & 1.34 & \\
\hline & \multicolumn{3}{|c|}{$(.23,2.20)$} & \multicolumn{3}{|c|}{$(.46,3.92)$} \\
\hline \multirow{2}{*}{$\begin{array}{l}\text { Edu [master } \\
\text { or higher] }\end{array}$} & -.59 & .55 & & .56 & 1.74 & \\
\hline & \multicolumn{3}{|c|}{$(.15,2.00)$} & \multicolumn{3}{|c|}{$(.56,5.43)$} \\
\hline \multirow{2}{*}{$\begin{array}{l}\text { GC self- } \\
\text { efficacy }\end{array}$} & -.38 & .68 & & -.33 & .72 & \\
\hline & \multicolumn{3}{|c|}{$(.31,1.50)$} & \multicolumn{3}{|c|}{$(.36,1.45)$} \\
\hline \multirow{2}{*}{$\begin{array}{l}\text { Music self- } \\
\text { efficacy }\end{array}$} & .94 & 2.55 & * & .38 & 1.46 & \\
\hline & \multicolumn{3}{|c|}{$(.99,6.56)$} & \multicolumn{3}{|c|}{$(.68,3.13)$} \\
\hline \multirow{2}{*}{$\begin{array}{l}\text { Music } \\
\text { expertise }\end{array}$} & .87 & 2.40 & & 1.55 & 4.70 & ** \\
\hline & \multicolumn{3}{|c|}{$(.88,6.55)$} & \multicolumn{3}{|c|}{$(1.87,11.82)$} \\
\hline \multirow{2}{*}{$\begin{array}{l}\text { Information } \\
\text { seeking }\end{array}$} & -.81 & .45 & * & -.14 & .87 & \\
\hline & \multicolumn{3}{|c|}{$(.20,0.99)$} & \multicolumn{3}{|c|}{$(.46,1.63)$} \\
\hline \multirow{2}{*}{$\begin{array}{l}\text { Social } \\
\text { Connected }\end{array}$} & 1.20 & 3.31 & & .52 & 1.67 & \\
\hline & \multicolumn{3}{|c|}{$(1.61,6.80)$} & & $2,3.04$ & \\
\hline $\begin{array}{l}\text { McFadden } \\
R^{2}\end{array}$ & .19 & & & & & \\
\hline
\end{tabular}

Social motive and information motive were strong predictors of holding a membership of informal music groups. Participants who value social connectedness were $331 \%$ more likely to be an informal music group member. However, participants who were motivated to seek information around music were $45 \%$ less likely to be a member of informal groups. Gender and music-technology self-efficacy were significantly associated with being an informal music group member. The positive and significant effect of gender could be caused by the structure of the 
sample (see Figure 1). There were no cohort effects on informal group membership.

Neither social nor information motives predicted formal music group membership. Two control variables, age and music expertise, were significantly associated with holding a formal membership. Music expertise had the largest odds ratio - participants with formal music training were $470 \%$ more likely to be a member of formal music group. It implied that rather than being motivated to seek information and maintain socially active, participants with more advanced musical expertise had a higher possibility of being a formal group member. This resonated with our preliminary ethnographic findings that formal and informal group participants had different levels of music proficiency, which might be the effect of the different standards of music aspiration of the groups or individual interests and gratifications. We will contextualise this further in the discussion section.

\subsection{User Identification of Music Group Participants}

We then investigated the heterogeneity of participants by breaking the sample into a "member group" and a "non-member group". Participants with either formal or informal group memberships were grouped in the "member group". Three logistic regressions were conducted to study the influence of motivations on user identification of two popular digital music products: YouTube and Spotify. We used three binary dependent variables in the regressions respectively: "users of both YouTube and Spotify" (Y\&S in Table 5, 1 - being users of both YouTube and Spotify, 0 - not using neither YouTube or Spotify), "YouTube users only" (1being YouTube users, 0 - not being YouTube users), and "Spotify users only" (Spotify in Table 5, 1- being Spotify users, 0 - not being Spotify users). Results of "YouTube users only" were not reported in Table 5, as only marginal effects were found. All coefficients were standardised in Table 5.

Of the two motivations, only social connectedness was significantly associated with the identification of Y\&S and Spotify users only. A positive $\beta$ indicated that participants who value social connectedness were $260 \%$ more likely to identify themselves as both YouTube and Spotify users, and were $285 \%$ more likely to identify themselves as Spotify users. We further tested the effect of motivations on user identification of YouTube and Spotify with the informal membership sample, the formal membership sample, and the non-member group respectively. No significant results were found from the non-member group membership sample. However, social motivation was significantly associated with the identification of Y\&S user and Spotify user from the informal membership sample. This further confirmed findings in 4.2 and 4.3 that those who wished to maintain social connectedness with others were more likely to be a member of informal groups and identify themselves as users of these digital music products. This is unsurprising because YouTube and Spotify have been regarded as socially connected and accessible products [31]. Prior research on YouTube use among the elderly showed that older adults were passive consumers rather than contributors of YouTube [43]. Our findings implied that the use and motivation of YouTube and Spotify was dependent on contextual and social factors, such as whether the use was related to group activities. The interrelation between group membership and use will be discussed further with the prior qualitative findings in the discussion section.

Table 5: Motivations influence on user identification

\begin{tabular}{|c|c|c|c|c|}
\hline & \multicolumn{2}{|c|}{ Y\&S } & \multicolumn{2}{|c|}{ Spotify } \\
\hline & $\beta$ & OR & $\beta$ & OR \\
\hline & \multicolumn{2}{|c|}{ 95\% Cl (LB-UB) } & \multicolumn{2}{|c|}{$\mathbf{9 5} \% \mathrm{Cl}$ (LB-UB) } \\
\hline \multirow[t]{2}{*}{ (Intercept) } & -.43 & .01 & -.12 & .02 \\
\hline & \multicolumn{2}{|c|}{$(.00,4.93)$} & \multicolumn{2}{|c|}{$(.00,19.01)$} \\
\hline \multirow[t]{2}{*}{ Age } & -.16 & .99 & .13 & 1.01 \\
\hline & \multicolumn{2}{|c|}{$(.91,1.08)$} & \multicolumn{2}{|c|}{$(.92,1.11)$} \\
\hline \multirow[t]{2}{*}{ Gender } & -.16 & .85 & -.23 & .80 \\
\hline & \multicolumn{2}{|c|}{$(.20,3.66)$} & \multicolumn{2}{|c|}{$(.18,3.49)$} \\
\hline \multirow{2}{*}{$\begin{array}{l}\text { Edu [under- } \\
\text { graduate] }\end{array}$} & .27 & 1.19 & .81 & 1.67 \\
\hline & \multicolumn{2}{|c|}{$(.26,5.52)$} & \multicolumn{2}{|c|}{$(.37,8.03)$} \\
\hline \multirow{2}{*}{$\begin{array}{l}\text { Edu [master or } \\
\text { higher] }\end{array}$} & 25.43 & 1.93 & 28.63 & 2.10 \\
\hline & \multicolumn{2}{|c|}{$(.41,9.79)$} & \multicolumn{2}{|c|}{$(.45,10.80)$} \\
\hline \multirow[t]{2}{*}{ GC self-efficacy } & .27 & 1.01 & -.97 & .98 \\
\hline & \multicolumn{2}{|c|}{$(.95,1.07)$} & \multicolumn{2}{|c|}{$(.92,1.03)$} \\
\hline \multirow[t]{2}{*}{ Music self-efficacy } & .00 & 1.00 & .02 & 1.02 \\
\hline & \multicolumn{2}{|c|}{$(.96,1.06)$} & \multicolumn{2}{|c|}{$(.97,1.07)$} \\
\hline \multirow{2}{*}{$\begin{array}{l}\text { Music } \\
\text { expertise }\end{array}$} & 1.01 & 1.46 & -.65 & .79 \\
\hline & \multicolumn{2}{|c|}{$(.36,6.15)$} & \multicolumn{2}{|c|}{$(.18,3.18)$} \\
\hline \multirow[t]{2}{*}{ Information seeking } & .30 & 1.11 & .15 & 1.06 \\
\hline & \multicolumn{2}{|c|}{$(.59,2.15)$} & \multicolumn{2}{|c|}{$(.56,2.02)$} \\
\hline \multirow{2}{*}{$\begin{array}{l}\text { Social } \\
\text { Connectedness }\end{array}$} & 14.04 & 2.60 & 15.45 & 2.85 \\
\hline & \multicolumn{2}{|c|}{$(1.45,5.13)$} & \multicolumn{2}{|c|}{$(1.56,5.82)$} \\
\hline $\begin{array}{l}\text { Hosmer\&Lemeshow } \\
R^{2}\end{array}$ & .25 & & .24 & \\
\hline
\end{tabular}

Information seeking did not play a large role in the user identification of YouTube or Spotify. We only found marginal effects of information seeking on YouTube only user identification (Odds Ratio = $.44, C I=[.17,1.03], p<0.1)$. One explanation was that our participants who were members of music groups did not rely on digital music services to seek music-related information. Likewise, self-efficacy did not correlate with the probability of being a Spotify or YouTube user among music group members. It implied that our participants perceived that they were able to use these services when they wished to. 


\section{DISCUSSION}

\subsection{Motivations of Digital Music Technology Adoption}

One consistent trend across the data above concerns the relationship between participants' motivation of maintaining social connectedness and their perceived use patterns of digital music technologies. The exploration of use patterns in Table 2 pointed to a set of socialised use around music and music-related activities (i.e., comment, rate, email about music). Moreover, we found that the motivation of social connectedness was significantly associated with more frequent perceived use and sharing with digital music technologies. Interestingly, among music group participants, social connectedness is a strong predictor of whether the participants regard themselves as Spotify (or YouTube) users. Taken together, participants identify themselves as digital music technology users and use these technologies more frequently for the purpose of maintaining social connectivity.

Information seeking did not seem to be a strong motivation in the overall data, however it could be important among some set of participants. In our analysis in 4.3 (see Table 4), information seeking was negatively associated with the likelihood of being a member of informal music groups. Prior studies with younger samples suggested that YouTube could be appropriated as a supporting tool and information hub for those who practice music $[29,31]$. However, our results with middle-aged and older adults did not confirm these findings. One explanation resonated with Sayago et al.'s study [43], that older adults relied more on conventional communication channels (e.g., face-to-face and email) for getting and sharing information. In groups with stronger focuses on social gathering (i.e., informal music groups in our case), people are more likely to account on their groups for information, as it has been implied in the group norms.

The quantitative data should be interpreted and contextualised alongside ethnographic and interview data obtained from our previous study and related literature $[5,36]$. As concerns the motivation of social connectedness, interviewees reported how they were "recruited" and attracted to local community music groups via established social networks. As one interviewee put it: "This [name of the informal singing group] is much more like a process, about people being included, their voices being ... more as a sense of community and singing for the moment". When discussing the experiences of participation, they also reported their "social" encounter with cloud technologies and streaming services that were new to them. For example, one participant (in our prior interview) noted the "social pressure" of using YouTube:
I was forced to learn how to use YouTube, because the choir people keep saying "Oh there is a wonderful recording on YouTube and listen to that." Whereas before I have never brought it to (my life) ... to look at YouTube. ...but I never use it (YouTube) as a listening device.

As concerns the experiences of learning, listening to music and performing in informal or formal music groups, our participants spoke of their awareness of streaming technologies and of how their early adoption was related to a sense of competence:

I've heard of [SoundCloud] from [name of the group leader]. I know what streaming is. I am very proud, since we are streaming. So, somebody uploaded that [music] onto [the site] $\ldots$ and then you could just play it.

Our prior interview data confirmed the explanation above with regard to the relationship between information motive and technology use. Being informed via word-of-mouth and conventional ways of communication (i.e., "online conversations via email") is common among music group members. Our findings confirmed what Sayago et al. [43] found about YouTube use among a group of senior citizens in a computer clubhouse. Also, the functionality of discovering music provided by digital music services were not well recognised among our participants. In the interview data the participants tended to discover music in conventional ways (i.e., listening to the music programme on the radio) and word-of-mouth from their singing group leaders and performing repertoires. For example, one interviewee mentioned that she occasionally got ideas of what music to purchase when she went to "some workshops during which the leaders were selling CDs". As such, our data and the triangulation with prior qualitative findings address the criticised validity of the U\&G approach ([44] cited in [42]) by contextualising U\&G motivations in situated usage and activities.

\subsection{Group Membership and Social Identity}

Our data points to the influence of music group membership and participation on the use of digital music technologies. First, participants with informal or formal music group membership tended to use digital music technologies more often for sharing music and active interacting with music. The link was even stronger than the association with social connectedness (Table 3). Socialising uses, such as commenting on music, rating music online, and communicating with e-mail around the topics of music showed no significant difference between members and non-members. Second, we found differences in the exploratory factors of informal and formal membership: informal music group participation was significantly correlated to social connectedness and music-technology self-efficacy; however, formal music group participation was only 
associated with more advanced music expertise. The finding was identical to our prior ethnographic results that formal music groups had a boundary in terms of music proficiency, even if such groups created "social spaces" for its participants as well. Third, the association between social connectedness and whether participants were Spotify and YouTube users were only significant within music groups.

Whichever type of membership, the key point to highlight is that we have clear evidence that holding a group membership was associated with more frequent use of digital music technologies and the higher likelihood of identifying oneself as a user of related digital music technologies. As we noted before, this relationship can be grounded in the psychological significance of social identity. A selfcategorisation approach helps to explain the various levels in which groups and social identities shape perception and action. At a perception level, social identification assists mutual intimacy among group members [21], provides attachment and meanings, and enables a sense of others as a source of recognition and support [7]. Participants with a shared identify of music groups tend to engage in group activities continuously. The music education literature (i.e., [12] ) adopts this strand of thought, and provides a conceptual model regarding mechanisms that underlie the relationship between community music participation and wellbeing in old age [11]. At the level of action, the group that one belongs to impacts the "psychological field" of oneself and shapes the behaviour that is perceived to be meaningful for present and future participation [21]. Carroll's conceptual model of community (cited in [7]), as we noted in the introduction, contextualised the action-level identification with community participation. Carroll argued that people tended to engage in "public visible activities" because of the awareness of shared meanings. As a consequence, informal help with technology emerged in the forms of new roles for the community (i.e., seniors as sources of wisdom [6] and specialists with technological skills [7]). In the case of our data, the practice of sharing music within groups was meaningful for participation and created awareness in the group. We found that one's music group participation was a predictor of the degree to which meaningful actions around technology use were conducted. Future research should also consider different types of membership other than music and what are "meaningful" actions for which type of membership.

\subsection{Self-Efficacy: Not a Usability Problem}

Neither general computer (GC) self-efficacy nor music-technology self-efficacy presented significant prediction effects on use and sharing with digital music technologies. Music-technology self-efficacy is the measurement of participants' felt capability of completing tasks around digital music technologies. This means that the barrier or unwillingness of using digital music technologies is not due to usability issues, even if our participants regarded it was. In a broader sense, this finding is unsurprising, as research in other domains and age groups also pointed to the importance of culture and meanings of technology development over technology per se. Rosner realised on her way of advocating a technological tool in support of knitting that "it was not online tools themselves that prompted bewilderment or anxiety for participants, but the development of the broader culture of technology development that was beginning to erase the contributions of bodies marked as aged and other" [41].

In our data, we only found that music-technology self-efficacy was positively associated with the probability of belonging to informal music groups. This is a weaker link than social motivation (see Table 4). It implied two things: first, it is relevant to note that informal music groups usually focus on the social enjoyment of group music making. Music sharing by sending and receiving music files and links, as a typical practice in informal groups, implies being connected with the group and is sustained with digital music technologies. Drawn from the social practice theory [45], the practical knowledge and know-how of digital music services accumulate over time and may contribute to a higher level of competence in doing so. Second, although our scale emphasises music-specific self-efficacy and makes sense in this research setting of particular practices around music participation, they are not all about features of popular online music services. This is likely to introduce measurement error. Future research should explore the effect of feature-based self-efficacy on the adoption of a particular type of technology or product.

\subsection{Age: Really an Issue of Technology Adoption?}

Our findings show that age is a relevant factor but not a prominent one with regard to the adoption of digital music technologies. For both age groups (those younger than 55 and those aged 55 and above), social and instrumental (informational) motivations are the most significant drivers of adopting digital music technologies. Technological tools that sustain the meaningful engagement with others and interaction with music are more likely to be adopted, as they sustain the situated needs associated with the use behaviour. The prominent role of social motivation in our study confirmed literature that examines motivating factors of digital music technologies with younger samples [27]. Our findings advance the understanding of social motivation in terms of age in three ways: (i) social connectedness is one of the primary motivating factors for both younger and older adults; (ii) subtler 
motivations related to social connectedness may differ for age-related reasons. For example, younger people often value the self-expression motivation around the use of digital music technologies, whilst in our prior ethnographic study self-expression and self-status was seldom reported; (iii) young and older adults may prefer different media to implement their social connectedness motivation: in-app sharing or posting links on Facebook are popular among younger adults [22,27], whereas older participants rely on conventional ways of sharing such as e-mail and face-to-face communication. Also, our study challenges the "myths of ageing" by showing that there are no significant differences between middle-aged and older people in terms of music technology use. Variations in motivations and social identity may affect use behaviours. Therefore, merely considering cohort effects is insufficient to unpack the motivations and uses of technology for the elderly.

\subsection{Limitations}

We are not suggesting that our study explains everything about the use and motivation of digital music technologies for the middle-aged and senior citizens. First of all, this survey measured selfreported perceived use frequency rather than behavioural data. Future research may consider analysing log data of digital music systems, or behavioural data of e-mail communication for the purpose of music.

Second, our selection of online survey respondents may imply a sampling bias. We oversampled older participants who were active Internet users or were interested in completing tasks on online crowdsourcing platforms. It is possible that people who participated were more likely to use online services and ICTs. Given that the perceived confidence of using computers is associated with the actual use and perceived use of computers [9], we measured and controlled for general computer self-efficacy. We believed that this measurement helps mitigate the effects of sampling bias.

Third, our data was cross-sectional, therefore we were unable to make strong claims about the causality of the predictors. Also, shared identity, as the self-categorisation approach suggested, is shaped by the environment and interaction with others and may form a feedback loop [21] between identity and behaviour (i.e., technology use). Therefore, we suspect that the increased use of digital music technologies further reinforces the sense of belonging. This means that we need to be sensitive when drawing conclusions about shared identity and group participation. The effect of shared identity and group participation was supported with our prior qualitative data. This highlights the role of shared identity as a key predictor and encourages future research into the consequences of group participation.

\section{CONCLUSIONS}

Digital music technologies are used and adopted in different ways by different users with different motivations. We found that social motivation was among the most important factors of using digital music technologies and was strongly associated with perceived use patterns and sharing behaviours. Music group participation contributed to more frequent use and higher probability of using digital music technologies (e.g., YouTube and Spotify). Our study adds to the digital music technology literature by providing an empirical case of situated technology use among middle-aged and older people and highlights the heterogeneity of this population. Our contextualisation and triangulation of survey results may prompt further discussion around the situated use and adoption of emerging technologies among the ageing population.

\section{ACKNOWLEDGEMENTS}

We would like to thank Professor Alan F. Blackwell (University of Cambridge), Dr Peng Liu (Tianjin University) and Tanja Schomann (University of Cambridge) for their constructive and insightful feedback on this research and earlier versions of the manuscript.

\section{REFERENCES}

1. Icek Ajzen. 2002. Perceived Behavioral Control, Self-Efficacy, Locus of Control, and the Theory of Planned Behavior. Journal of Applied Social Psychology 32, 4: 665-683. https://doi.org/10.1111/j.15591816.2002.tb00236.x

2. Brydie-Leigh Bartleet and Lee Higgins. 2018. The Oxford Handbook of Community Music. Oxford University Press.

3. Alan F. Blackwell. 2015. $\mathrm{HCl}$ as an InterDiscipline. In Proceedings of the 33rd Annual ACM Conference Extended Abstracts on Human Factors in Computing Systems, 503-516. http://dl.acm.org/citation.cfm?id=2732505

4. Robin Brewer, Meredith Ringel Morris, and Anne Marie Piper. 2016. Why would anybody do this?: Understanding Older Adults' Motivations and Challenges in Crowd Work. In Proceedings of the $2016 \mathrm{CHI}$ Conference on Human Factors in Computing Systems, 2246-2257. http://dl.acm.org/citation.cfm?id=2858198

5. Robin Brewer and Anne Marie Piper. 2016. "Tell It Like It Really Is": A Case of Online Content 
Creation and Sharing Among Older Adult Bloggers. In Proceedings of the $2016 \mathrm{CHI}$ Conference on Human Factors in Computing Systems (CHI '16), 5529-5542. https://doi.org/10.1145/2858036.2858379

6. John M. Carroll, Gregorio Convertino, Umer Farooq, and Mary Beth Rosson. 2012. The firekeepers: aging considered as a resource. Universal access in the information society 11, 1: 7-15.

7. John M. Carroll and Mary Beth Rosson. 2013. Wild at Home: The Neighborhood As a Living Laboratory for $\mathrm{HCl}$. ACM Trans. Comput.-Hum. Interact. $\quad 20, \quad 3: \quad 16: 1-16: 28$. https://doi.org/10.1145/2491500.2491504

8. Mu-Chien Chou and Chin-Hua Liu. 2016. Mobile Instant Messengers and Middle-Aged and Elderly Adults in Taiwan: Uses and Gratifications. International Journal of Human-Computer Interaction 32, 11: 835-846.

9. Deborah Compeau, Christopher A. Higgins, and Sid Huff. 1999. Social Cognitive Theory and Individual Reactions to Computing Technology: A Longitudinal Study. MIS Quarterly 23, 2: 145-158. https://doi.org/10.2307/249749

10.Deborah R. Compeau and Christopher A. Higgins. 1995. Computer Self-efficacy: Development of a Measure and Initial Test. MIS quarterly: 189-211.

11.Andrea Creech, Susan Hallam, Hillary McQueen, and Maria Varvarigou. 2013. The Power of Music in the Lives of Older Adults. Research Studies in Music Education 35, 1: 87-102. https://doi.org/10.1177/1321103X13478862

12.Andrea Creech, Susan Hallam, Maria Varvarigou, Hilary McQueen, and Helena Gaunt. 2013. Active Music Making: a Route to Enhanced Subjective Well-being Among Older People. Perspectives in Public Health 133, 1: 36-43. https://doi.org/10.1177/1757913912466950

13. L. Damodaran, C. W. Olphert, and J. Sandhu. 2014. Falling Off the Bandwagon? Exploring the Challenges to Sustained Digital Engagement by Older People. Gerontology 60, 2: 163-173. https://doi.org/10.1159/000357431

14.Fred D. Davis. 1989. Perceived Usefulness, Perceived Ease of Use, and User Acceptance of Information Technology. MIS quarterly: 319-340.

15.Alexa Doebele. 2012. Technology and the Choral Art: Music in the Cloud for the Modern Choral Director. The Choral Journal 53, 5: 91-95.

16.Paul Dourish. 2003. The Appropriation of Interactive Technologies: Some Lessons from Placeless Documents. Computer Supported Cooperative Work (CSCW) 12, 4: 465-490.
17. Susan M. Ferreira, Sergio Sayago, and Josep Blat. 2017. Older People's Production and Appropriation of Digital Videos: An Ethnographic Study. Behaviour \& Information Technology 36, 6: 557-574.

https://doi.org/10.1080/0144929X.2016.1265150

18. Frank J. Floyd and Keith F. Widaman. 1995. Factor Analysis in the Development and Refinement of Clinical Assessment Instruments. Psychological assessment 7, 3: 286.

19. Joseph F. Hair, William C. Black, Barry J. Babin, Rolph E. Anderson, and Ronald L. Tatham. 1998. Multivariate Data Analysis. Prentice Hall Upper Saddle River, NJ.

20.Susan Hallam, Andrea Creech, Maria Varvarigou, and Hilary McQueen. 2012. The Characteristics of Older People Who Engage in Community Music Making, Their Reasons for Participation and the Barriers They Face. Journal of Adult and Continuing Education 18, 2: 21-43. https://doi.org/10.7227/JACE.18.2.3

21. Nick Hopkins, Stephen D. Reicher, Sammyh S. Khan, Shruti Tewari, Narayanan Srinivasan, and Clifford Stevenson. 2016. Explaining Effervescence: Investigating the Relationship Between Shared Social Identity and Positive Experience in Crowds. Cognition and Emotion 30, $1: 20-32$. https://doi.org/10.1080/02699931.2015.1015969

22.Mayur Karnik, lan Oakley, Jayant Venkatanathan, Tasos Spiliotopoulos, and Valentina Nisi. 2013. Uses \& Gratifications of a Facebook Media Sharing Group. In Proceedings of the 2013 Conference on Computer Supported Cooperative Work (CSCW '13), 821-826. https://doi.org/10.1145/2441776.2441868

23. Elihu Katz, Jay G. Blumler, and Michael Gurevitch. 1973. Uses and Gratifications Research. Public Opinion Quarterly 37, 4: 509523. https://doi.org/10.1086/268109

24. Aniket Kittur, Ed H. Chi, and Bongwon Suh. 2008. Crowdsourcing User Studies with Mechanical Turk. In Proceedings of the SIGCHI Conference on Human Factors in Computing Systems (CHI '08), 453-456. https://doi.org/10.1145/1357054.1357127

25. Masatomo Kobayashi, Shoma Arita, Toshinari Itoko, Shin Saito, and Hironobu Takagi. 2015. Motivating Multi-Generational Crowd Workers in Social-Purpose Work. In Proceedings of the 18th ACM Conference on Computer Supported Cooperative Work \& Social Computing, 18131824. http://dl.acm.org/citation.cfm?id=2675255

26. Amanda E. Krause and Adrian C. North. 2014. Music Listening in Everyday Life: Devices, Selection Methods, and Digital Technology. 
Psychology of Music: 0305735614559065. https://doi.org/10.1177/0305735614559065

27. Amanda E. Krause, Adrian C. North, and Brody Heritage. 2014. The Uses and Gratifications of Using Facebook Music Listening Applications. Computers in Human Behavior 39: 71-77. https://doi.org/10.1016/j.chb.2014.07.001

28. Amanda E. Krause, Adrian C. North, and Lauren Y. Hewitt. 2015. Music-listening in everyday life: Devices and choice. Psychology of Music 43, 2: 155-170.

https://doi.org/10.1177/0305735613496860

29.Nathan B. Kruse and Kari K. Veblen. 2012. Music Teaching and Learning Online: Considering YouTube Instructional Videos. Journal of Music, Technology \& Education 5, 1: 77-87.

30.Tuck W. Leong and Peter C. Wright. 2013. Revisiting Social Practices Surrounding Music. In Proceedings of the SIGCHI Conference on Human Factors in Computing Systems (CHI '13), 951-960.

https://doi.org/10.1145/2470654.2466122

31.Lassi A. Liikkanen and Pirkka Åman. 2015. Shuffling Services: Current Trends in Interacting with Digital Music. Interacting with Computers 28, 3: 352-371.

32.Joseph Lindley, Paul Coulton, and Miriam Sturdee. 2017. Implications for Adoption. In Proceedings of the $2017 \mathrm{CHI}$ Conference on Human Factors in Computing Systems (CHI '17), 265-277.

https://doi.org/10.1145/3025453.3025742

33. Mao Mao, Alan F. Blackwell, Johanna M. Lukate, and David A. Good. 2016. Supporting Retirement Socially and Musically by Technology: An Ethnographic Study of Local Community Musicians. In Proceedings of the $2016 \mathrm{CHI}$ Conference Extended Abstracts on Human Factors in Computing Systems, 2886-2892. Retrieved June 10, 2016 from http://dl.acm.org/citation.cfm?id=2892285

34.Shelley McKeown, Reeshma Haji, and Neil Ferguson. 2016. Understanding Peace and Conflict Through Social Identity Theory: Contemporary Global Perspectives. Springer.

35.Anne-Sophie Melenhorst, Wendy A. Rogers, and Don G. Bouwhuis. 2006. Older Adults' Motivated Choice for Technological Innovation: Evidence for Benefit-Driven Selectivity. Psychology and Aging 21, 1: 190-195. https://doi.org/10.1037/08827974.21.1.190

36. Fabio Morreale, Giulio Moro, Alan Chamberlain, Steve Benford, and Andrew P. McPherson. 2017. Building a Maker Community Around an Open Hardware Platform. In Proceedings of the 2017 $\mathrm{CHI}$ Conference on Human Factors in Computing
Systems (CHI '17), 6948-6959. https://doi.org/10.1145/3025453.3026056

37. Kellie Morrissey, Andrew Garbett, Peter Wright, Patrick Olivier, Edward lan Jenkins, and Katie Brittain. 2017. Care and Connect: Exploring Dementia-Friendliness Through an Online Community Commissioning Platform. In Proceedings of the $2017 \mathrm{CHI}$ Conference on Human Factors in Computing Systems ( $\mathrm{CHI}$ '17), 2163-2174.

https://doi.org/10.1145/3025453.3025732

38.Kathryn M. Orzech, Wendy Moncur, Abigail Durrant, Stuart James, and John Collomosse. 2017. Digital Photographic Practices as Expressions of Personhood and Identity: Variations Across School Leavers and Recent Retirees. Visual Studies 32, 4: 313-328. https://doi.org/10.1080/1472586X.2017.1362959

39.Kathryn M. Orzech, Wendy Moncur, Abigail Durrant, and Diego Trujillo-Pisanty. 2016. Opportunities and Challenges of the Digital Lifespan: Views of Service Providers and Citizens in the UK. Information, Communication \& Society $0,0: 1-16$.

https://doi.org/10.1080/1369118X.2016.1257043

40.Stephen Reicher and Nick Hopkins. 2016. Perception, Action, and the Social Dynamics of the Variable Self. Psychological Inquiry 27, 4: 341-347.

https://doi.org/10.1080/1047840X.2016.1217584

41. Daniela Rosner. 2016. Conflicting Ideologies of the Digital Hand: Locating the Material in a Digital Age. In Critical Craft: Technology, Globalization, and Capitalism. Bloomsbury Publishing, 189-198.

42.Thomas E. Ruggiero. 2000. Uses and Gratifications Theory in the 21st Century. Mass Communication and Society 3, 1: 3-37. https://doi.org/10.1207/S15327825MCS0301_02

43. Sergio Sayago, Paula Forbes, and Josep Blat. 2012. Older People's Social Sharing Practices in YouTube Through an Ethnographical Lens. In Proceedings of the 26th Annual BCS Interaction Specialist Group Conference on People and Computers (BCS-HCl '12), 185-194. http://dl.acm.org/citation.cfm?id=2377916.237793 7

44. Werner Joseph Severin and James W. Tankard. 2001. Communication Theories: Origins, Methods, and Uses in the Mass Media. Pearson College Division.

45. Elizabeth Shove. 2007. The Design of Everyday Life. Berg.

46.Roger Silverstone. 2006. Domesticating Domestication. Reflecting on the Life of a Concept. In Domestication of media and 
technology. Open University Press, Maidenhead, UK, 229-248.

47. Joanne R. Smith, Terry Deborah J., Manstead Antony S. R., Louis Winnifred R., Kotterman Diana, and Wolfs Jacqueline. 2007. Interaction Effects in the Theory of Planned Behavior: The Interplay of Self-Identity and Past Behavior. Journal of Applied Social Psychology 37, 11: 2726-2750. https://doi.org/10.1111/j.15591816.2007.00278.x

48.Lucy Suchman. 2007. Human-machine Reconfigurations: Plans and Situated Actions. Cambridge University Press.

49. Lucy Suchman. 2002. Practice-based Design of Information Systems: Notes from the Hyperdeveloped World. The information society 18, 2: 139-144.

50. Henri Tajfel. 2010. Social Identity and Intergroup Relations. Cambridge University Press.

51. Nick Taylor, Ursula Hurley, and Philip Connolly. 2016. Making Community: The Wider Role of Makerspaces in Public Life. In Proceedings of the
$2016 \mathrm{CHI}$ Conference on Human Factors in Computing Systems (CHI '16), 1415-1425. https://doi.org/10.1145/2858036.2858073

52.Shirley Taylor and Peter A. Todd. 1995. Understanding Information Technology Usage: A Test of Competing Models. Information systems research 6, 2: 144-176.

53. John Vines, Gary Pritchard, Peter Wright, Patrick Olivier, and Katie Brittain. 2015. An Age-Old Problem: Examining the Discourses of Ageing in $\mathrm{HCl}$ and Strategies for Future Research. ACM Transactions on Computer-Human Interaction (TOCHI) 22, $1: 2$.

54. Xuan Zhao and Siân E. Lindley. 2014. Curation Through Use: Understanding the Personal Value of Social Media. In Proceedings of the $32 \mathrm{Nd}$ Annual ACM Conference on Human Factors in Computing Systems (CHI '14), 2431-2440. https://doi.org/10.1145/2556288.2557291

55. World Health Organisation. Active Aging - A Policy Framework. 2002. Retrieved from http://www.who.int/ageing/publications/active_age ing/en/ 